\title{
Child Sexual Abuse and Adolescent and Adult Adjustment: A Review of British and World Evidence, with Implications for Social Work, and Mental Health and School Counselling
}

\author{
Alice Sawyerr ${ }^{1}$, Christopher Bagley² \\ ${ }^{1}$ Department of Continuing Education, University of Oxford, Oxford, UK \\ ${ }^{2}$ Public Health Institute, Liverpool John Moores University, Liverpool, UK \\ Email: chrisbagley2@gmail.com, sawyerr.aaa@gmail.com
}

How to cite this paper: Sawyerr, A., \& Bagley, C. (2017). Child Sexual Abuse and Adolescent and Adult Adjustment: A Review of British and World Evidence, with Implications for Social Work, and Mental Health and School Counselling. Advances in Applied Sociology, 7, 1-15.

http://dx.doi.org/10.4236/aasoci.2017.71001

Received: October 3, 2016

Accepted: December 31, 2016

Published: January 3, 2017

Copyright $\odot 2017$ by authors and Scientific Research Publishing Inc. This work is licensed under the Creative Commons Attribution International License (CC BY 4.0).

http://creativecommons.org/licenses/by/4.0/

\section{c) (i) Open Access}

\begin{abstract}
We offer a narrative review of the findings of available British research on the sexual abuse of children, and its behavioural and mental health sequels in adolescent and adult adjustment, and link this to the growing world literature on child abuse, which frequently occurs within family settings. The evidence shows that around $9 \%$ of women, and about $3 \%$ of men have experienced prolonged, bodily intrusive abuse by the age of 16 or 18 . This has many adverse sequels including impaired self-esteem, clinical levels of depression and anxiety, self-harm and substance abuse, somatic disorders, and many forms of maladaptation. Poly-victimisation combining physical, sexual and emotional abuse has particularly negative impacts. The long-term burden in human suffering and public health costs is high. In school, abuse victims are often bullied and isolated in school, which exacerbates (or even triggers) the negative effects of abuse. Teachers and school counsellors and social workers have an important role to play in identifying abuse victims, and offering help in ways which prevents the development of serious mental health problems.
\end{abstract}

\section{Keywords}

Sexual Abuse, Physical Abuse, Emotional Abuse, Child Victims, Bullying, School Counselling, Adult Mental Health, United Kingdom

\section{Introduction}

The purpose of this review article is to educate human relations professionals 
(particularly in Britain, where we are educators and mental health professionals), concerning recent and very important work on the long-term mental health sequels of child sexual (and other) abuse. These studies have profound implications for how secondary school teachers, counsellors and social workers should organise their work, and relate to pupils and clients. We stress that this is not a systematic meta-analysis, but the development of an argument based on published research in one European country, in understanding the implications of these findings for professional education and policy planning. Our approach is based on child-centred, critical realism. Critical realism is usefully defined by Bryman (2016) as "...A realist epistemology that asserts that the study of the social world should be concerned with the identification of the structures that generate the world. Critical realism is 'critical' because its practitioners aim to identify structures in order to change them, so that inequalities and injustices may be counteracted" (Bryman, 2016: p. 690). Thus from the outset we start with the value presumption that child sexual abuse is not only a hidden crime, but it is also morally wrong, and is embedded in the implicit values of sexist social structures. Our research and teaching is not value free, but seeks to engage in active, morphogenetic social change (Archer, 2014).

Our opinion, as professional educators, is that front-line practitioners should be fully conversant with clinical, forensic and epidemiological research which has implications for their practice, and for this reason we had earlier produced systematic summaries of the North America research and clinical literature for practitioners (Bagley \& Thurston, 1996). The bulk of the work reviewed here is British, but we link these studies to relevant findings from other cultures, which have particular significance in interpreting and evaluating these British findings.

\subsection{Earlier British Research on Forms of Child Abuse, Its Incidence and Its Long-Term Effects}

Compared with North America (Finkelhor, 1979), the British literature on child maltreatment is fairly recent. But the published work from Britain is of good quality, and offers several avenues for further research and intervention. The first located study is that of Baker \& Duncan (1985) who reported findings from a brief question about any kind of unwanted sexual contact in childhood, in a national random sample of 2019 individuals: 12 per cent of women, and 8 percent of men recalled such abusive events, but no further details were available on the nature of the abuse. The next study of note comes from Scotland (Gillham et al., 1998). This research team examined a large data set of referrals for child maltreatment (physical abuse and neglect, and sexual abuse) in Glasgow in the early-1990s, measured against a backdrop of a sudden rise in unemployment. They found a clear link between a rise in abuse referrals, and a rise in unemployment, especially in traditionally low-income areas. This "sub-cultural" effect, in deprived urban areas, also emerged in the English work of Coid et al. (2001) who in research with 1207 women registered with GPs in London, found 
that those who in childhood had experienced combinations of physical and sexual abuse, were four times more likely than other women of similar age and social class, to have been subject as adults, to domestic violence, and rape in various settings.

In contrast, Oaksford \& Frude (2001) studied 213 English female undergraduates using questionnaires, and found that $28(13 \%)$ had experienced various types of sexual abuse in their childhood or teenage years. They comment on the generally good mental health of this group, and the fact that they were successfully coping with tertiary education. This and other research shows that there can be "survivors" of even the grossest forms of abuse, provided that it is not combined with other forms of abuse. Thus in the large-scale follow-up of a large cohort identified child victims of child sexual abuse-CSA (probably combined with other forms of abuse) in Britain, had diagnosable psychiatric disorders which were more than four times the rate in individually matched, non-abused controls (Spataro et al., 2004).

One disturbing feature of children and adolescents experiencing chronic chaos at home-witnessing family violence, substance abuse, and the physical and sexual assaults of others, and experiencing such assaults themselves-was that of running from home (Meltzer et al., 2012). These researchers examined the life-histories of a subsample of 2247 individuals in the English Psychiatric Morbidity Survey, and reported that seven percent of this group had run from home before the age of 16-the rate in girls was double that in boys. In this population of runaways, 45 percent had been physically maltreated prior to running, 25 per cent witnessed frequent family violence, and nine percent were subjected to sexual penetration. After running, both males and females were at high risk for suicidal behaviour, and of being drawn into the worlds of commercial sex, drug use, and drug-dealing.

\subsection{The NSPCC Studies}

The work commissioned by the English NSPCC (National Society for the Prevention of Cruelty to Children) between 1998 and 2009 provides the most comprehensive available studies on the prevalence of child maltreatment, and the social contexts in which it takes place (Radford et al., 2011; Radford, 2013; Radford et al., 2013). The first NSPCC survey was of a large random sample in 1998, of British adults aged 18 - 24. The second survey in 2009 was more ambitious and asked questions about prior events of abuse not only of young adults, but also of the parents and caretakers of some 4000 children.

The comparison of the young adult samples of 1998 and 2008-9 is instructive, since the same set of questions applied to large random samples of the British population at both points in time, clearly showed that the prevalence of various forms of physical abuse, physical and emotional neglect and sexual violence was declining, and this welcome movement was clear statistically significant. We reproduce some of these results below: 


\begin{tabular}{ccccc}
\hline & \multicolumn{2}{c}{ Any physical violence } & \multicolumn{2}{c}{ Any coercive sexual abuse } \\
\hline Males & 1998 & 2009 & 1998 & 2009 \\
Females & $13.4 \%$ & $10.9 \%$ & $3.7 \%$ & $1.6 \%$ \\
"Middle class" & $13.1 \%$ & $9.0 \%$ & $9.9 \%$ & $8.5 \%$ \\
"Working class" & $11.5 \%$ & $9.0 \%$ & $5.7 \%$ & $4.3 \%$ \\
2-parent family & $18.2 \%$ & $13.1 \%$ & $10.2 \%$ & $7.2 \%$ \\
1-parent or in care & $10.2 \%$ & $7.9 \%$ & $5.3 \%$ & $3.2 \%$ \\
\hline
\end{tabular}

Source of data in above table: Radford et al. (2011).

This research shows that there is indeed a class bias in the experience of physical and sexual abuse, which also occurs with greater frequency in disorganized family settings. The small but statistically significant decline in the amount of sexual abuse might be due to greater media publicity about high-profile abusers (children knowing more about, and being able to avoid CSA), and greater awareness of teachers and other professionals, as well as the introduction of relevant teaching in schools about avoiding CSA. But that is speculation, and difficult to prove. Lorraine Radford and her team included a number of mental health measures in the 2009 survey of young adults, and reported, for example, a six-fold increase in suicidal ideas and self-harm in prior victims of CSA: "There were strong associations between maltreatment, sexual abuse and physical violence with poorer emotional well-being, including self-harm and suicidal thoughts, demonstrating the need for prevention and earlier intervention to protect young people from harm" (p. 122).

\section{3. "Poly-Victims" and the Possibility of Enduring Neurological Changes Caused by Child Maltreatment}

The idea of children being victims of multiple types of abuse, and as a result are at much greater risk of adverse mental health problems was identified in the review by Finkelhor et al. (2007) of mainly American research, and he coined the term poly-victimization. This idea had also been developed by Bagley \& Mallick (2000a \& 2000b) in their Canadian longitudinal study of a cohort studied from birth to age 17. They identified several interacting predictors of poor mental health at age 17: developmental problems identified at birth (including CNS problems); emotional abuse of the child; and/or physical abuse and/or sexual abuse. According to their developmental model the marginal child is often emotionally neglected and abused in the preschool period, with overlapping physical punishments and abuse, with first episode of sexual abuse (often in a family setting) occurring from about age eight through to adolescence.

Such children already had very low self-esteem before the sexual abuse began, and they often lacked feelings of competence and self-worth which would have enabled them to ask the abuser to stop, or to seek help. Children with good self-esteem, and no prior history of emotional and physical abuse, were usually able to report, and/or put a stop to, initial attempts at sexual exploitation. That 
was why, Bagley \& Mallick (2000b) argued, brief episodes of sexual abuse did not usually impair the child's mental health and self-esteem. These and similar findings were confirmed in the review by Anda et al. (2006) which showed: “...the enduring effects of abuse and related adverse experiences in childhood ... from studies of neurobiology and epidemiology".

According to Radford et al. (2011) in their English national survey, there is an overlap between types of abuse, emotional, physical and sexual: "Children and young people who are poly-victims are an extremely vulnerable group. Early identification of, and intervention with these young people is needed to prevent both immediate and long-term problems" (p. 122). In commenting further on these results, and reviewing more recent studies, Radford (2013) observed that: "Self-blame, self-harm and suicide are commonly mentioned as consequences of sexual abuse". She cites the challenging American research of Alexander (2011) that prolonged and severe sexual abuse in childhood creates a "neurological syndrome" in which epigenetic pathways may be biochemically triggered in the nervous system causing brain changes, which can lead to a life of prolonged sadness, incipient terrors, chronic guilt, and self-debasing activities which may be lifelong in nature, based on neuro-imagining studies (Ischebeck et al., 2009).

Chou (2012) confirmed the enduring, negative effects of child sexual abuse on older people in an English community sample of 3493 individuals aged over 50, including many who were 70 or older. CSA (defined as sexual touching or penetration over a relatively long period, had occurred in $8 \%$ ) was significantly linked across the lifespan to anxiety and depression (which were often comorbid), PTSD, suicidal ideas and self-harm, and periods of psychiatric hospitalization. The combination of different types of abuse was particularly likely to predict lifelong psychiatric morbidity.

Bebbington et al. (2011a, 2011b) found that in the 7353 adults in an English survey of psychiatric morbidity, indicators of early-onset psychosis were ten times the expected rate in those experiencing prolonged and intrusive sexual abuse up to age 16. The development of chronic and severe depression and anxiety was a predictor of the development of this psychosis. The prior abuse is causally implicated in the development of this most serious form of mental illness, the authors conclude, and epigenetic factors may be involved in that the chronically abused child has developed a chronic neurological disorder in which the psyche "withdraws" from everyday interactions and information processing.

The neurological problems imposed on the CNS of the developing child who is subjected to prolonged, severe and multiple forms of abuse have been identified in the American work of Teicher et al. (2012) who studied 183 young adults, using MRI brain scans: 16 percent had been subjected to three or more kinds of abuse (sexual, physical emotional, experiencing parental violence) for prolonged periods. Teicher et al. observe that "The exquisite vulnerability of the hippocampus to the ravages of stress is one of the key translational neuroscience discoveries of the twentieth century". Their work showed "reduced volume in the hippocampal subfields CA3, dentate gyrus, and subiculum" in the poly-victims. 
British psychiatrists Morgan \& Gayer-Anderson (2016) reviewed both British and world literature on the potential causal links between childhood adversity and abuse, school experiences including bullying, early adult maladjustment, and the onset of psychosis. Statistically speaking, child abuse "survivors" have a more than three-fold increase in rates of chronic psychosis. They conclude from the long-term follow-up studies analysed that: "There is a substantial body of evidence of associations between various forms of childhood adversity and psychosis". The variety of adverse experiences, ranging from poly-victimisation, through school bullying, and early adult trauma caused by abuse-led self-harming behaviours, are interactive and synergistic in causing permanent neurological and psychological changes in a minority of CSA victims, which can be direct, causal precursors of psychosis.

\section{The Physical and Sexual Abuse of Children Is an International Public Health Problem}

That child physical and sexual abuse is an international problem of public health is shown by Gilbert et al. (2009) who examined studies using comparable methodology in "high income countries" (including the UK), and concluded that about 8 or 9 percent of children will suffer physical abuse, 10 percent will experience physical or emotional neglect, and some 7 percent of females and 3 percent of males will experience prolonged, often penetrative, sexual abuse. Moreover, these events can have mental health sequels in adulthood which are very costly for the individuals, and for health and social care systems. Yet these events, they point out, are hardly recognised as major public health problems, and systems of prevention, and the identification and treatment of child victims are not well-developed in any country.

The extent of these problems in Britain has been emphasised by the research of Bebbington et al. (2011a, 2011b) whose team surveyed British 7353 adults who completed a laptop questionnaire, on unwanted sexual contacts up to age 16: 11.1 percent of women, and 5.3 percent in males recalled such abuse. These figures included brief and non-recurring sexual assaults: nevertheless, the mental health burden upon some victims in adult life made this, clearly, "a public health problem". The authors note too that the rate of sexual abuse doubled when the child was not in a conventional two-parent family. As Radford et al. (2011) showed sexual assaults of the incestuous type are actually quite rare: when CSA did occur within families, it was usually older brothers, or "mother's boyfriend" who were the perpetrators.

\subsection{Child and Adolescent Sexual Abuse in Deprived and Disrupted Family and Community Settings}

The epidemiological work reviewed above suggests that most sexual assault of female children and adolescents is not of the classic "incest" type, but is often perpetrated by unrelated adults who have access to women and children in disorganised families. Victims may have been physically and sexually abused and 
emotionally neglected within disorganised one-parent families under stress (e.g. Gillham et al., 1998), but sexual victimisation also takes place in community, school, or other settings. It is clear from British research in forensic psychiatry (Pritchard \& Bagley, 2001 \& 2000; Bagley \& Pritchard, 2000) that persistent sex offenders and paedophiles prey on vulnerable children in various settings (including becoming "partners" of single parents), and may become very adept at doing so, with multiple victims.

The risks to vulnerable children is emphasised in the important research of Lereva et al. (2015) in their report of the 4026 individuals retained in the Avon Birth Cohort study, followed up to age 24. Parents gave information of their social situations, and their relationships with the focus child at ages 8, 10 and 13 in terms of their child's experience of physical, emotional and sexual harm. While parents often admitted to their imperfections as carers in terms of physical and emotional care, it was rare for them to admit to any within-family sexual exploitation of the child, although they did report this when it was perpetrated outside of the family. Interviewed as young adults, the children in this birth cohort largely corroborated parental reports.

This study showed that single events of sexual assault were not usually harmful for the child's mental health (perhaps because the ethical procedures of the research required adequate therapy or referral when abuse was detected in one of the earlier data sweeps). Parental reports of events of physical abuse (e.g. parentally inflicted "punishments") were not associated with lasting mental health problems. However, these researchers found a synergistic effect for maltreatment at home combined with bullying and physical and sexual assaults carried out in or around the school. Many children and adolescents could, seemingly, survive within-family abuse and neglect: but when this was combined with bullying, harassment and assault in school settings there was a significant mental health burden in terms of clinical levels of depression (8\%), anxiety (10\%) and suicidality (9\%).

The authors comment on these results: "The insufficiency of resources for bullying compared with those for family maltreatment requires attention. It is important for schools, health services and other agencies to co-ordinate their responses to bullying, and research is needed to assess such interagency policies and procedures" (Lereva et al., 2015: p. 525).

One implication of this research is that schools as institutions (e.g. through teacher, counsellor and social work resources) can help these vulnerable and often marginalised students to have a supportive peer network, which is clearly a crucial part of their psychological recovery. Instead, the abused child is often a loner, a misfit, a suitable person to be excluded from peer networks, a person to be sneered at, bullied, hit, sexually molested and even raped. From Lereva et al.'s (2015) research, this is clearly a particular problem for female victims. Finkelhor \& Tucker (2015) who edited the special issue of the journal in which Lereva's research was published, comment on both American, and this British research: "Molestation, rape, exposure to domestic violence, corporal punishment, physi- 
cal abuse, bullying, sexual molestation ... all overlap. 'Peer violence' is part of this 'maltreatment syndrome"' (p. 481).

\subsection{Peer Settings, Support, and Abuse}

That the young person's world outside the family can be of crucial importance is emphasised by the study by Jackson et al. (2016) of 73013 to 16 year olds, the study's literature review observing that "There has been little research carried out in the United Kingdom aimed at providing a holistic exploration of the victim experiences of young people within the school and community environments" (p. 343). Their research found that many of the adolescents had experienced some form of victimization outside of the family, within the past year. In school one in three had property vandalised or stolen; one in two had experienced verbal harassment or physical bullying; one in 28 experienced "dating violence" including rape and sexual assault, and one in seven had been victims of sexual assault or harassment in school settings. Moreover, these types of assault on person or property tended to overlap. Bagley \& King (2003) reflecting on their Canadian research suggest that it is likely that the female victims of multiple assaults were marginal to peer networks, and once sexually assaulted gained the reputation of being "an easy lay" or a "slut", subjected to verbal and physical assaults from both males and females.

Girls themselves may be involved in the bullying and sexual harassment of other girls, according to the interesting work in two London comprehensives by Jamal et al. (2015) which used a qualitative design in examining the "social ecology" of bullying spaces, which often involved sexual rivalries, and sexual denigration of peers.

\subsection{Male Victims}

Male victims of sexual and physical assault in childhood and adolescence have been less intensively studied, but work suggests that some may be better able to "shrug off" both physical assaults, and the attempts at sexual assault by older males. Only when the boy's sexuality is put in doubt (e.g. "enjoying" imposed gay sex) are there likely to be early reactions in terms of suicidality and self harm (Bagley \& Tremblay, 2000). But young transgender males who are seduced by unscrupulous, older males, gay or otherwise, have greatly increased rates of self-harm, drug-use, and school absences (Bagley \& D'Augelli, 2000).

Salter et al. (2003) who studied 224 male victims of sexual assault in childhood and adolescence found in a 7 to 19 year follow-up after the original referral for psychiatric treatment, that 26 (11.6\%) had become sexual abusers themselves (of both male and female children). Statistically significant predictors of this "victim-to-abuser" cycle were material and emotional neglect in childhood, and being sexually assaulted by a female. A psychodynamic explanation might invoke the idea of oedipal guilt in the young boy, and his inability to have sexual relations with adult women ${ }^{1}$.

${ }^{1}$ For case examples, and possible psychodynamic accounts of the relatively rare phenomenon of consummated incest, see Bagley (1969) and Pincus \& Dare (1978). 


\subsection{Longitudinal Studies}

Several British longitudinal studies have yielded information which confirms English epidemiological work on the long-term negative effects of child abuse of various kinds. The National Child Development Study followed up some 11,500 individuals born in a single week in 1958 and has yielded numerous reports of early antecedents of factors in child and adult development. Clark et al. (2010) reported that by the time the cohort was aged 45 , there were clear links between recollections of earlier sexual and physical abuse, and adult psychopathology, especially when the two types of abuse were combined. A study of Rutter's longitudinal cohort of children born in 1968 found that by 2009 "harsh parenting", and CSA in various settings were linked to adult neuroticism and suicidality, especially when the two types of abuse had both occurred (Pickles et al., 2010). Further support for these longitudinal research findings comes from the work of Sidebotham et al. (2006).

\subsection{Further English Epidemiological Studies of the Long-Term Sequels of Child Maltreatment}

Methodologically sophisticated English studies using large samples continue to appear, and emphasise that childhood victimization is a major, but still unaddressed, public health problem. Bellis, Lowey \& Leckenby (2014) used a specifically public health model in designing and analysing the results of a national English survey of 3885 adults aged 18 to 69 , which focussed on "adverse childhood events". These included parental quarrelling and violence, parental absence, family violence directed towards child, verbal abuse of child, sexual assaults on the child, mental illness and/or drug and alcohol misuse in a caretaker, criminal conviction and imprisonment of a caretaker or sibling: $8.3 \%$ of those surveyed had experienced four or more of these adverse events in childhood.

Such a history was associated with a greatly elevated risk of poor adult mental health, substance abuse, and behavioural problems including criminality in the adult lives of those who had experienced highly stressed childhoods. These problems were manifested in particular, in individuals living in deprived urban areas. In reading yet another depressing English national survey, one is prompted to pose the questions: What of the children of these now adult victims? What is this new generation's history of abuse, in the "cycle of deprivation" described by Rutter \& Madge (1976)? What kinds of schools were the children in this cycle of deprivation attending, and how could these schools identify and address their problems, and break the "cycle of alienation" described by Williams \& Pritchard (2006)?

Using their public health model, Bellis et al. (2014) show that adverse childhood events explained, in adulthood: $11.9 \%$ of adult binge drinking; $5 \%$ of heroin use; $38 \%$ of unwanted teenaged pregnancy; and $14 \%$ of poor diet and poor personal health care. Reducing the incidence of adverse childhood events they argue, would be a highly productive public health strategy. On adverse mental health outcomes, they argue that: "Links between such behaviours and child- 
hood circumstances are likely to operate through the impact of adverse childhood events on the developing brain and its stress regulatory systems, which affect factors such as emotional regulation and fear response, and this may predispose individuals to health-harming behaviours" (p. 90).

\subsection{World Literature}

World-wide reviews of literature on CSA research are now being published, and these both include in their review, the growing body of good-quality British research, and also offer verification of the British findings. Maniglio (2009) in a "review of reviews" identified some 270,000 individuals included in 587 reliable studies². Maniglio concluded that: "There is evidence that survivors of childhood sexual abuse are significantly at risk of a wide range of medical, psychological, behavioral and sexual disorders ... child sexual abuse should be considered as a general, nonspecific risk factor for psychopathology ... with multiple implications for research, treatment and health policy" (p. 644). Similar findings come from the international review by Barth et al. (2013). The international literature on CSA and its sequels in somatic disorder has been reviewed by Paras et al. (2009), again showing a clear and probably causal link between earlier abuse and later psychopathology.

No country is immune from this major public health problem: Chen et al. (2010) for example report rates of CSA of 14.1 percent in females in China, with significant links to adult depression, anxiety, paranoid ideation, and other psychiatric disorders.

\section{Conclusions from the Literature Review on Child and Adolescent Maltreatment: Implications for School Organisation and Counselling}

It is clear that in Britain, as elsewhere in the world, the maltreatment and neglect of children, physically, sexually, emotionally which takes place in family and community, is an important public health problem with lifelong negative consequences in terms of depression, anxiety, suicidality, psychosomatic disorders, post-traumatic stress disorder, psychosis, substance misuse, and self-defeating lifestyles. While up to a half of child and adolescent victims survive without manifesting overt psychological symptoms, a half do not. This implies that future research on resilience to abuse, and potential protective and early therapeutic factors is important.

Combinations of abuse, physical and sexual are particularly likely to have adverse mental health outcomes: about four percent of females will have experienced not merely contact abuse, but also chronic, intrusive (penetrative) sexual abuse combined with either physical abuse, emotional abuse, or all of these. This recent British research confirms the results of the Canadian longitudinal work of ${ }^{2}$ It is worth mentioning that our Canadian study of a random sample of adults (Bagley \& Ramsay, 1986) was the first epidemiological, general population survey to establish a link between increased rates of psychiatric disorder, and prior sexual abuse in childhood and adolescence. This study has been cited several hundred times. 
Bagley \& Mallick (2000a \& 2000b). Barth et al put the matter thus in their review of world literature thus: "Nine girls and three boys out of 100 are victims of forced intercourse". Sometimes this is a single incident of rape; for a minority however, the forced intrusion of the child's body will continue for months and even years.

While the British researchers, who are mainly child and adult psychiatrists, focus on diagnosable mental health conditions, there are grounds for assuming that an individual with depression, anxiety and self-harm who falls into the clinical domain, would also have very low self-esteem. In terms of William James' (1890) model of the body as being at the centre of self-concept and selfesteem: the violation of the child's body through physical and sexual abuse interferes profoundly with core developments of the self-concept, and the evaluative construct of self-esteem, the innate feelings of "goodness" or "badness" by which the child develops a self-schema (Bagley, 1995). The abused child acquires an identity which often moves on a particular trajectory, one of watchfulness, fear, nightmare, nervousness, a pattern "burned into the brain", even causing permanent structural brain changes which last a lifetime (Bagley \& King, 2003; Alexander, 2011).

Reflecting on the qualitative research reviewed by Bagley (1997) we argue that at school, their peers "know" that this child is different: this child has been dominated, and in school they are once again dominated. School should be a haven, but too often it is an arena of fear in which the child is again bullied, sneered at, hit, sexually handled, lewdly suggested, forced unwillingly in her state of learned helplessness into further dominated and sexualized relationships. Her very will is raped. In the worst case, her body belongs not to her but to others, to kick around and prod as they please.

The dramatis persona of the victim which we have sketched may seem exaggerated and over-dramatized. But is it? For up to one in twelve female adolescents in Britain (as in other countries) it seems a frightful reality, as the evidence we have identified seems to show. School cultures can make things worse rather than better for the child victim.

The literature reviewed has important implications for the organisation of secondary schools. They should be arenas in which children who experience the onset of being bullied, emotionally, physically and sexually-have immediate access to help which can end this abuse, and offer counselling to victims. Many of the victims of school bullying will have been victims of physical, emotional and sexual abuse, and school counsellors have thus a triple task: to end the bullying by aspects of school management and organisation; to end ongoing abuse taking place outside of the school; and to offer long-term counselling, include expert referral for mental health counselling, which will be often needed to prevent the adolescent becoming an adult whose low self-esteem, depression and other symptoms may signal a lifetime pattern of poor mental health.

Demonstration projects which introduced additional counsellors, teachers and social workers into a secondary school's core team have shown that with active 
planning and generous, extra resources such interventions can be both successful, and highly cost effective (Bagley \& Pritchard, 1998a \& 1998b; Williams \& Pritchard, 2006). These special interventions should be focussed on secondary schools in deprived urban areas, in which sub-cultures of social disorganisation and trans-generational abuse and family dysfunction often coexist (Bagley, 2008). But we note too the review by Euser et al. (2015) of 27 randomised clinical trials aimed either at preventing re-abuse in identified victims, or in preventing abuse occurring in high risk families. Such studies indicate "small but significant positive effects" in preventing various forms of child maltreatment, but only in programmes which engaged families and victims over a long period of time, and/or with contact therapy hours above the median for the programmes reviewed. Accepting this finding, we would point to the important role of schools in early identification of victims, and in preventing the bullying of child victims, which clearly adds to the long-term burden of sexual abuse. Research, prevention and therapy should be intensive, and focussed on multiple institutions and goals.

\section{References}

Alexander, R. (2011). Introduction to Special Section: Medical Advances in Child Sexual Abuse. Part 2. Journal of Child Sexual Abuse, 20, 607-611. https://doi.org/10.1080/10538712.2011.623686

Anda, R. F., \& Six Others (2006). The Enduring Effects of Abuse and Related Adverse Experiences in Childhood: A Convergence of Evidence from Neurobiology and Epidemiology. European Archives of Psychiatry and Clinical Neuroscience, 256, 174-180. https://doi.org/10.1007/s00406-005-0624-4

Archer, M. (2014).Late Modernity: Trajectories towards Morphogenesis. New York: Springer. https://doi.org/10.1007/978-3-319-03266-5

Bagley, C. (1969). Incest Behavior and Incest Taboo. Social Problems, 16, 505-519. https://doi.org/10.2307/799958

Bagley, C. (1995). Early Sexual Experience and Sexual Victimization of Children and Adolescents. In G. Rekers (Eds.) Handbook of Child and Adolescents Sexual Problems (pp. 135-163). New York: Lexington Books.

Bagley, C. (1997). Children, Sex and Social Policy: Humanistic Solutions for Problems of Child Sexual Abuse. Aldershot: Ashgate.

Bagley, C. (2008). The Educational and Social Inclusion of Disadvantaged Students. In C. Bagley, \& G. Verma (Eds.), Challenges for Inclusion: Educational and Social Studies from Britain and the Indian Sub-Continent (pp. 103-148). Rotterdam: Sense Educational Publishers.

Bagley, C., \& D’Augelli, A. (2000). Gay, Lesbian and Bisexual Youth Have Elevated Rates of Suicidal Behaviour: An International Problem Associated with Homophobia and Homophobic Legislation. British Medical Journal, 320, 1617-1618.

https://doi.org/10.1136/bmj.320.7250.1617

Bagley, C., \& King, K. (2003). Child Sexual Abuse: The Search for Healing. London and New York: Routledge-Taylor and Francis.

Bagley, C., \& Mallick, K. (2000a). Spiralling up and Spiralling Down: Implications of a Long-Term Study of Temperament and Conduct Disorder for Social Work with Children. Child and Family Social Work, 5, 291-301. 
https://doi.org/10.1046/j.1365-2206.2000.00178.x

Bagley, C., \& Mallick, K. (2000b). Prediction of Sexual, Emotional and Physical Maltreatment and Mental Health Outcomes in a Longitudinal Cohort of 290 Adolescent Women. Child Maltreatment, 5, 218-226. https://doi.org/10.1177/1077559500005003002

Bagley, C., \& Pritchard, C. (1998a). The Reduction of Problem Behaviours and School Exclusion in At-Risk Youth: An Experimental Study of School Social Work with Cost-Benefit Analyses. Child and Family Social Work, 3, 219-226. https://doi.org/10.1046/j.1365-2206.1998.00101.x

Bagley, C., \& Pritchard, C. (1998b). The Billion Dollar Cost of Troubled Youth: Prospects for Cost-Effective Prevention and Treatment. International Journal of Adolescent and Youth, 7, 211-225. https://doi.org/10.1080/02673843.1998.9747825

Bagley, C., \& Pritchard, C. (2000). Criminality and Violence in Intra- and Extra-Familial Child Sexual Abusers in a 2-Year Cohort of Convicted Perpetrators. Child Abuse Review, 9, 264-274. https://doi.org/10.1002/1099-0852(200007/08)9:4<264::AID-CAR635>3.0.CO;2-6

Bagley, C., \& Ramsay, R. (1986). Sexual Abuse in Childhood: Psychosocial Outcomes and Implications for Social Work Practice. Journal of Social Work and Human Sexuality, 4, 33-47. https://doi.org/10.1300/J291v04n01 07

Bagley, C., \& Thurston, W. (1996). Understanding and Preventing Child Sexual Abuse Volume I: Children-Assessment, Social Work and Clinical Issues, and Prevention Education. Volume II Male Victims, Adolescents, Adult Outcomes and Offender Treatment. Aldershot: Ashgate, Arena Social Work Publications.

Bagley, C., \& Tremblay, P. (2000). Elevated Rates of Suicidal Behaviour in Gay, Lesbian and Bisexual Youth: Estimates of Prevalence and an Account of Causes. Crisis: Journal of Crisis Intervention and Suicide Prevention, 21, 111-117. https://doi.org/10.1027//0227-5910.21.3.111

Baker, A., \& Duncan, S. (1985). Child Sexual Abuse: A Study of Prevalence in Great Britain. Child Abuse and Neglect, 9, 457-467. https://doi.org/10.1016/0145-2134(85)90054-7

Barth, J., Bermetz, L., Heim, E., Trelle, S., \& Tonia, T. (2013). The Current Prevalence of Child Sexual Abuse Worldwide: A Systematic Review and Meta-Analysis. International Journal of Public Health, 58, 469-483. https://doi.org/10.1007/s00038-012-0426-1

Bebbington, P. et al. (2011a). Child Sexual Abuse Reported by an English National Sample: Characteristics and Demography. Social Psychiatry and Psychiatric Epidemiology, 46, 255-262. https://doi.org/10.1007/s00127-010-0245-8

Bebbington, P. et al. (2011b). Childhood Sexual Abuse and Psychosis: Data from a CrossSectional Psychiatric Survey in England. British Journal of Psychiatry, 199, 29-37. https://doi.org/10.1192/bjp.bp.110.083642

Bellis, M. A., Hughes, K., Leckenby, N., Perkins, C., \& Lowey, M. (2014). National Household Survey of Adverse Childhood Experiences and Their Relationship with Resilience to Health-Harming Behaviour in England. BMC Medicine, 12, 72-100.

https://doi.org/10.1186/1741-7015-12-72

Bellis, M., Lowey, H., \& Leckenby, N. (2014). Adverse Childhood Experiences: Retrospective Study to Determine Their Impact on Adult Health. Journal of Public Health, 36, 81-91. https://doi.org/10.1093/pubmed/fdt038

Bryman, A. (2016). Social Research Methods (5th ed.). London: Oxford University Press.

Chen, J., Han, P, Lian, G., \& Dunne, M. (2010). Prevalence of Childhood Sexual Abuse 
among 2508 College Students in 6 Provinces of China. Chinese Journal of Epidemiology, 31, 866-869. (Article in Chinese, Accessed through PubMed English-Language Abstract)

Chou, K. L. (2012). Childhood Sexual Abuse and Psychiatric Disorders in Middle-Aged and Older Adults: Evidence from the 2007 Adult Psychiatric Morbidity Survey. Journal of Clinical Psychology, 73, e1365-e1371. https://doi.org/10.4088/jcp.12m07946

Clark, C., Caldwell, T, Power, C., \& Stansfield, C. (2010). Does the Influence of Childhood Adversity on Psychopathology Persist across the Life-Course? A 45-Year Prospective Epidemiological Study. Annals of Epidemiology, 20, 385-394.

https://doi.org/10.1016/j.annepidem.2010.02.008

Coid, J. Petruckevitch, A., Feler, G., Chung, W. S., \& Richardson, J. (2001). Relation between Childhood Sexual and Physical Abuse and Risk of Revictimisation in Women. The Lancet, 358, 450-454. https://doi.org/10.1016/S0140-6736(01)05622-7

Euser, S., Alink, L., Stoltenborgh, M., Bakermans-Kroneberg, M., \& Ijzendoorn, M. (2015). A Gloomy Picture: A Meta-Analysis of Randomly Controlled Trials Reveals Disappointing Effectiveness of Programs Aiming at Preventing Child Maltreatment. BMC Public Health, 15, 1068-1075. https://doi.org/10.1186/s12889-015-2387-9

Finkelhor, D. (1979). Sexually Victimized Children. New York, NY: The Free Press.

Finkelhor, D., \& Tucker, C. J. (2015). A Holistic Approach to Child Maltreatment. The Lancet Psychiatry, 6, 480-481. https://doi.org/10.1016/S2215-0366(15)00173-X

Finkelhor, D., Ormrod, K., \& Turner, H. A. (2007). Poly-Victimization: A Neglected Component in Child Maltreatment. Child Abuse and Neglect, 31, 7-26. https://doi.org/10.1016/j.chiabu.2006.06.008

Gilbert, R., Widom, C. S., Kevin, B., David, F., Elspeth, W., \& Staffan, J. (2009). Burden and Consequences of Child Maltreatment in High Income Countries. The Lancet, 373, 68-81. https://doi.org/10.1016/S0140-6736(08)61706-7

Gillham B., Tanner, G, Cheyne, B, Freeman, I, Rooney, M, \& Lambie, A. (1998). Unemployment Rates, Single Parent Density and Indices of Child Poverty: Their Relationship to Different Categories of Child Abuse and Neglect. Child Abuse and Neglect, 22, 7990.

Ischebeck, A., Shocke, M., \& Delazer, M. (2009). The Processing and Representation of Fractions within the Brain: An fMRI Investigation. NeuroImage, 47, S89. https://doi.org/10.1016/s1053-8119(09)70693-7

Jackson, V., Browne, K., \& Joseph, S. (2016). The Prevalence of Childhood Victimization Experienced Outside of the Family: Findings from an English Prevalence Study. Child Abuse and Neglect, 51, 343-357. https://doi.org/10.1016/j.chiabu.2015.08.006

Jamal, F., Bonell, C., Harden, A., \& Lorenc, T. (2015). The Social Ecology of Girls' Bullying Practices: Exploratory Research in Two London Schools. Sociology of Health International, 37, 731-744. https://doi.org/10.1111/1467-9566.12231

James, W. (1890). Selections from the Principles of Psychology. In H. Thayer (Ed.), Pragmatism: The Classic Writings (pp. 135-179). New York, NJ: New American Library. https://doi.org/10.1037/11059-000

Lereva, S. T., Copeland, W. E., Costello, I. J., \& Wolke, D. (2015). Adult Mental Health Consequences of Peer Bullying and Maltreatment in Childhood: Two Cohorts in Two Countries. The Lancet Psychiatry, 2, 524-531.

https://doi.org/10.1016/S2215-0366(15)00165-0

Maniglio, R. (2009). The Impact of Child Sexual on Health: A Systematic Review of Reviews. Clinical Psychology Review, 29, 647-657.

https://doi.org/10.1016/j.cpr.2009.08.003 
Meltzer, H., Ford, T., Bebbington, P., \& Vostanis, P. (2012) Children Who Run Away from Home: Risks for Suicidal Behaviour and Substance Misuses. Journal of Adolescent Health, 51, 415-422. https://doi.org/10.1016/j.jadohealth.2012.04.002

Morgan, C., \& Gayes-Anderson, C. (2016). Childhood Adversity and PsychosisEvidence, Challenges and Implications. World Psychiatry, 15, 95-102. https://doi.org/10.1002/wps.20330

Oaksford, K., \& Frude, N. (2001). The Prevalence and Nature of Child Sexual Abuse: Evidence from a Female University Sample in the UK. Child Abuse Review, 10, 49-59. https://doi.org/10.1002/car.663

Paras, M. et al. (2009). Sexual Abuse and Lifetime Diagnosis of Somatic Disorders: A Systematic Review and Meta-Analysis. Journal of the American Medical Association, 302, 550-561. https://doi.org/10.1001/jama.2009.1091

Pickles, A., Aglan, A., Collishaw, S., Messer, J., Rutter, M., \& Maughan, B. (2010). Predictors of Suicidality across the Lifespan: The Isle of Wight Study. Psychological Medicine, 40, 1453-1466. https://doi.org/10.1017/S0033291709991905

Pincus, L., \& Dare, C. (1978). Secrets in the Family. London: Faber.

Pritchard, C., \& Bagley, C. (2000). Multi-Criminal and Violent Groups among Child Sex Offenders: A Heuristic Typology in a 2-Year Cohort of Men in Two English Counties. Child Abuse and Neglect, 24, 579-586. https://doi.org/10.1016/S0145-2134(00)00108-3

Pritchard, C., \& Bagley, C. (2001). Suicide in Child Murderers and Child Sexual Abusers. Journal of Forensic Psychiatry, 12, 269-286. https://doi.org/10.1080/09585180110057208

Radford, L. (2013). Child Sexual Abuse: An NSPCC Research Briefing. London: National Society for the Prevention of Cruelty to Children.

Radford, L. et al. (2011). Child Abuse and Neglect in the United Kingdom Today. London: National Society for the Prevention of Cruelty to Children.

Radford, L., Corral, S., Bradley, C., \& Fisher, H. L. (2013). The Prevalence and Impact of Child Maltreatment in the United Kingdom. Child Abuse and Neglect, 37, 801-813.

Rutter, M., \& Madge, N. (1976).Cycles of Disadvantage. London: Heinemann.

Salter, D. et al. (2003). Development of Sexually Abusive Behaviour in Sexually Victimised Males: A Longitudinal Study. The Lancet, 361, 471-476. https://doi.org/10.1016/S0140-6736(03)12466-X

Sidebotham, P., Herson, J., \& ALSPAC Study Team (2006). Child Maltreatment in the "Child of the Nineties": A Cohort Study of Risk. Child Abuse and Neglect, 30, 497-522. https://doi.org/10.1016/j.chiabu.2005.11.005

Spataro, J., Mullen, P., Burgess, P., Wells, D., \& Moss, A. (2004). Impact of Child Sexual Abuse on Mental Health. British Journal of Psychiatry, 184, 416-421. https://doi.org/10.1192/bjp.184.5.416

Teicher, M., Anderson, C., \& Polcari, P. (2012). Childhood Maltreatment Is Associated with Reduced Volume in the Hippocampal Subfields, CA3, Dental Gyrus, and Subiculum. Proceedings of the National Academy of Sciences, 109, E563-E572. https://doi.org/10.1073/pnas.1115396109

Williams, R., \& Pritchard, C. (2006). Breaking the Cycle of Educational Alienation: A Multi-Professional Approach. Maidenhead: McGraw-Hill Educational. 
Submit or recommend next manuscript to SCIRP and we will provide best service for you:

Accepting pre-submission inquiries through Email, Facebook, LinkedIn, Twitter, etc. A wide selection of journals (inclusive of 9 subjects, more than 200 journals)

Providing 24-hour high-quality service

User-friendly online submission system

Fair and swift peer-review system

Efficient typesetting and proofreading procedure

Display of the result of downloads and visits, as well as the number of cited articles Maximum dissemination of your research work

Submit your manuscript at: http://papersubmission.scirp.org/

Or contact aasoci@scirp.org 